\title{
HINARI Access to Research in Health program networks to sustain and expand success
}

\author{
Karin Saric, MLIS \\ See end of article for author's affiliation.
}

DOI: http://dx.doi.org/10.3163/1536-5050.104.4.018

The HINARI Access to Research in Health program is one of four Research4Life (R4L) programs. R4L is a "a public-private partnership of the WHO [World Health Organization], FAO [Food and Agriculture Organization of the United Nations], UNEP [United Nations Environment Programme], WIPO [World Intellectual Property Organization], Cornell and Yale Universities, the International Association of Scientific, Technical \& Medical Publishers and over 200 international scientific publishers" [1]. R4L was created to reduce a significant knowledge gap in developing countries by providing free or low cost access to vital scientific knowledge. HINARI focuses on health research and was the first R4L program.

The acronym stands for Health Inter-Network Access to Research Initiative, although that name has been abandoned. The other R4L programs focus on research in agriculture, the environment, and development and innovation.

In 2010, the R4L partners conducted an infrastructure review and a user experience review to assess R4L programs and their influence on the participation of developing countries in the global research community [2]. The results of the user experience review confirmed that R4L programs deliver high value to their users, but results also revealed that "limited awareness" of and "challenges [in] finding relevant information" prevented optimal use of these programs. In response to these findings, the R4L partners implemented institutional-level initiatives, including the development of "networks amongst communities of practice, using regional and national platforms wherever possible" [2].

In the last decade, HINARI has evolved into a virtual learning center with the proven ability to bridge the global information divide. It is now one of the primary portals accessed by researchers in developing countries, and continued publisher support has been pledged through 2020 [3]. HINARI is currently administered by a small cadre of individuals who have worked proactively and synergistically to establish a solid foundation for the program [4]. As the program continues to grow, it is essential to determine how the success achieved thus far can be both sustained and expanded. This commentary proposes ways that networks within the Medical Library Association (MLA) and the National Library of Medicine (NLM) can be leveraged to increase awareness and usage training of HINARI.

\section{MEDICAL LIBRARY ASSOCIATION}

\section{Increased outreach via global health programs}

MLA's Librarians without Borders ${ }^{\circledR}$ (LWB) program was established in 2007 to provide training on a global level about information retrieval. As an R4L institutional partner, MLA is a central node in the HINARI network. As such, LWB members were instrumental in developing the HINARI train-thetrainers course to train individuals on how to access information from the HINARI portal. The course is funded via the Elsevier E-Library Training Initiative grant, and anyone who participates in the training becomes certified to train others. Nearly 100 MLA members are now certified instructors, and global training activities have been conducted through workshops in HINARI-eligible countries and via online distance learning courses to reach non-MLA individuals in the health care environment.

Concomitant with the development of MLA's global information training was a surge in the establishment of global health programs by academic institutions in developed countries. In addition to introducing vital medical information to developing countries, ethically driven global health programs also collaborate with local health care workers to generate and publish high-quality research [5]. Such collaborations serve to increase the contribution of knowledge from developing countries to the body of global medical literature. Unfortunately, awareness of the existence of HINARI and its valuable assets is still lacking, and HINARI is not utilized or promoted as much as it could be by global health programs from both developed and developing countries. As 
both librarians and global health workers play a role in the scholarly communication cycle, awareness and use of HINARI could be increased if librarians partner with global health programs to market and publicize HINARI. Librarians who have participated in the LWB program are well positioned in powerful redistribution points to facilitate the integration of HINARI into global health programs around the world.

\section{How librarians can help}

Librarians can use not only the extensive marketing materials created by R4L to raise awareness of HINARI resources in global health programs, but can also extend their outreach through a variety of additional methods. Institutions with wellestablished global health programs should host regional train-the-trainers workshops in which librarians, global health workers, and visitors from HINARI-eligible countries can become certified HINARI trainers. Institutions without the budget or capacity to plan such events can incorporate HINARI awareness or training into the predeparture training courses of their global health programs. Partnering with an institution's international student office and reaching out directly to visiting scholars are also effective ways to raise awareness. Visiting scholars can easily determine if their home institutions have access to HINARI by consulting the online list of participating institutions [6] or by reaching out directly to HINARI staff at hinari@ who.int.

\section{How global health workers can help}

Individuals who are interested in becoming trainers can complete the online "Train the Trainers" short course [7]. Those who are not interested in training can still promote awareness by informing eligible members about HINARI, recommending use of this resource in policy plans, or incorporating information mined from HINARI into health care services and programs. Most importantly, through this outreach, practitioners from global health programs will understand that HINARI is a highly valued, capacity-building resource for end users in developing countries and that it is a beneficial primary resource that supports their own efforts as well. With this knowledge, they can function as HINARI ambassadors and raise awareness via complementary channels that librarians are not reaching.

\section{Instructional modules}

HINARI was awarded MLA's 2015 Louise Darling Medal for Distinguished Achievement in Collection Development in the Health Sciences. Since its creation in 2002, the HINARI collection has grown from offering access to 1,500 journals to over 58,000 information resources, including popular databases such as Cochrane, Scopus, and CINAHL [8]. The HINARI portal also contains training modules that cover global health information topics, such as evidence-based practice, database searching, information literacy, and manuscript publication. The modules consist of PowerPoint presentations and Word documents containing hands-on exercises [4]. This instructional material is freely available to anyone and can easily be incorporated or adapted into local instructional material.

The difficulty, however, lies in identifying the content that is relevant to the local user community. First, one must understand that the instructional material is split between the HINARI [9] and R4L [10] training portals. Second, each module contains an extensive collection of resources. Librarians can make these valuable resources more visible and accessible by creating local guides highlighting information specific to the environment and end users [11].

Integration into global health programs and creation of resource guides are both bottom-up approaches to sustaining the success of HINARI. A more top-down approach could be taken by extending the information infrastructure into a networked, physical environment.

\section{NATIONAL LIBRARY OF MEDICINE}

Many factors have contributed to NLM's development of its global information infrastructure, including the creation of a national network of regional libraries across the United States.

Establishment of what is now known as the National Network of Libraries of Medicine (NN/LM), in conjunction with consulting and training services for local librarians, enabled NLM to deliver health information to resource-poor areas in a rapid and effective manner [12]. Looking beyond 2020, consideration should be given to the creation of a network of R4L regional centers in strategic geographic locations around the world, utilizing the framework used to develop NN/LM. The benefits provided by a network of fixed, central points of 
coordination could mitigate some of the issues that arise from serving a global community.

\section{HINARI TRAINING ACTIVITIES}

Since its inception, training has been emphasized as a key goal of the HINARI program. In addition to the train-the-trainers workshops, a short online course has been created to facilitate distance learning, video tutorials have been developed for end users, and a help center has been established to address individual needs. Training modules have been translated into several languages and integrated into institutional learning platforms, and new modules have been added as additional user needs have been identified. Training activities are coordinated by a variety of groups, including WHO staff in Geneva, Switzerland, WHO regional offices, and members of MLA's LWB initiative [4].

While training arrangements have been more ad hoc in other parts of the world, in Africa, the Information Training and Outreach Centre for Africa (ITOCA) has been an instrumental partner in coordinating R4L training courses across the entire Sub-Saharan region [4]. The existence of a central coordinating organization for training has facilitated the delivery of more than 100 courses to about 30 Sub-Saharan African countries [13]. Courses tailored to meet the needs of the participants have been taught in both face-to-face and distance learning modalities, and translated into a variety of languages [4]. Although there has been significant success, ongoing training is crucial to the viability of this program. Many potential end users have not been trained, and those who have been trained still face challenges in accessing relevant resources [2].

\section{NETWORK OF RESEARCH4LIFE REGIONAL CENTERS: EXTEND TRAINING AND PARTNERSHIPS}

The benefits of partnering with an organization such as ITOCA can be leveraged and extended to other parts of the world through a network of R4L regional centers. The ability to delegate coordination and training to a stable and dedicated staff would allow greater insight into and understanding of local needs and barriers and the ability to pull in information from local contexts. More specifically, training could be tailored to address the growing issue of countryspecific publisher exclusions that create challenges to access [2]. Instruction could also be expanded to include databases such as CINAHL and Scopus, which are not searchable via the PubMed platform. On a broader level, the constant proximity would allow the time and space needed to integrate information literacy skills training directly into the educational curriculum [4].

The consistency of a fixed regional center and staff would also allow partnerships to develop with other networks and institutions, such as (1) the Health Literature, Library and Information Services (HELLIS) network that connects over 350 libraries in 11 countries in southeast Asia [14], (2) the European Association for Health Information and Libraries [15], and (3) health sciences libraries with established programs focused on serving global communities. R4L regional centers could serve as pathways to incorporating instruction for other aspects of the research cycle, such as research design and statistical interpretation [5], or could provide a platform for implementing related programs created by partner institutions. Most important, however, would be the ability to partner with existing regional consortia networks to mitigate the rising costs of obtaining resources. Collaborations with regional consortia would allow for advocacy and support during publisher negotiations as countries move out of $\mathrm{R} 4 \mathrm{~L}$ eligibility status and transition into the commercial playing field.

Following the NN/LM model, establishment of $\mathrm{R} 4 \mathrm{~L}$ regional centers in universities or other prominent institutions, such as WHO regional offices or focal point libraries, could serve to mitigate the technological barriers of poor connectivity and limited bandwidth [2]. Certainly, such endeavors would require collaboration, funding, and coordination of many additional factors to succeed. Nevertheless, with a viable framework established by NN/LM and with Microsoft as a core technology partner, the creation of a network of regional centers should be included in the long-term plans of R4L.

By providing access to authoritative medical literature to developing countries, HINARI has become a valuable resource for developing countries around the world. A solid foundation has been established during the previous decade, and looking forward, it is important to identify how the success of this program can be sustained and expanded. Consideration should be given to the power of partner networks to scale the success of this program to a broader level. Promotion by MLA members can serve to help integrate HINARI into global health programs, while the creation of strategically located R4L regional centers can extend the success through 
a physical, networked infrastructure. This deeper integration into the global research environment will allow HINARI to continue supporting the growth of quality research and sharing scientific knowledge across multilateral channels around the world.

\section{REFERENCES}

1. Research4Life. About Research4Life [Internet]. 2016 [cited 14 Apr 2016]. <http://www.research4life.org/ about $/>$.

2. Gaible E, Gedye R, Ochs M, Parker K, Rudgard S. Research4Life: bringing academic and professional peerreviewed content to developing countries through publicprivate partnership [Internet]. Presented at: World Library and Information Congress: 77th International Federation of Library Associations and Institutions General Conference and Assembly; San Juan, PR; 13-18 Aug 2011 [cited 7 Dec 2015]. <http://conference.ifla.org/ past-wlic/2011/164-gaible-en.pdf $>$.

3. Van Essen C, Mizero P, Kyamanywa P, Cartledge P. HINARI grows: one step closer to health information for all. Trop Med Int Health. 2014 Jul;19(7):825-7. DOI: http:// dx.doi.org/10.1111/tmi.12310.

4. Rhine L. HINARI access to research initiativeoverview, impact and training activities [Internet]. Presented at: Positioning the Profession: the Tenth International Congress on Medical Librarianship; Brisbane, Australia; 31 Aug-4 Sep 2009 [cited 7 Dec 2015]. p. 1-8. < http://espace.library.uq.edu.au/view/UQ:179698/ n6_1_Fri_Rhine_103.pdf>.

5. Chu KM, Jayaraman S, Kyamanywa P, Ntakiyiruta G. Building research capacity in Africa: equity and global health collaborations. PLOS Med. 2014 Mar 11;11(3): e1001612. DOI: http://dx.doi.org/10.1371/journal.pmed. 1001612.

6. World Health Organization. HINARI participating academic institutions [Internet]. The Organization [cited
21 Jun 2016]. <http://www.who.int/hinari/faq/

Participating_Academic_Institutions_HINARI.pdf $>$.

7. Medical Library Association. Available courses

[Internet]. The Association [cited 21 Jun 2016]. <http://

mla.mrooms.org $>$.

8. HINARI. About HINARI [Internet]. [cited 21 Jun 2016]. $<$ http://www.who.int/hinari/about/en/>.

9. HINARI. Training [Internet]. [cited 21 Jun 2016].

$<$ http://www.who.int/hinari/training/>.

10. Research4Life. Training portal [Internet]. [cited 21 Jun 2016]. <http://www.research4life.org/training/>.

11. Norris Medical Library, University of Southern

California. Research4Life-HINARI: home [Internet]. The University [cited 21 Jun 2016]. <http://norris.usc.

libguides.com/R4L $>$.

12. Bunting A. The nation's health information network: history of the regional medical library program, 19651985. Bull Med Libr Assoc. 1987 Jul;75(3 suppl):1-62. 13. Information Training and Outreach Centre for Africa. Research4Life/TEEAL programmes courses [Internet].The Centre [cited 21 Jun 2016]. <http://www.itoca.org/node/ $81>$.

14. Health Literature, Library and Information Services (HELLIS). Index Medicus for South-East Asia Region (IMSEAR): about us [Internet]. [cited 21 Jun 2016]. $<$ http://imsear.hellis.org $>$.

15. European Association for Health Information and Libraries [Internet]. The Association [cited 21 Jun 2016].

$<$ http://www.eahil.eu $>$.

\section{AUTHOR'S AFFILIATION}

Karin Saric, MLIS, ksaric@usc.edu, Information Services Librarian, Educational \& Research Services, Norris Medical Library, University of Southern California, 2003 Zonal Avenue, Los Angeles, CA 90089-9130 